\title{
Article
}

\section{Effect of mechanical denaturation on surface free energy of protein powders}

Mohammad, Mohammad Amin, Grimsey, Ian M., Forbes, Robert Thomas, Blagbrough, lan S. and Conway, Barbara R

Available at http://clok.uclan.ac.uk/15855/

Mohammad, Mohammad Amin, Grimsey, Ian M., Forbes, Robert Thomas ORCID: 0000-0003-3521-4386, Blagbrough, Ian S. and Conway, Barbara R (2016) Effect of mechanical denaturation on surface free energy of protein powders. Colloids and Surfaces B: Biointerfaces, 146 . pp. 700-706. ISSN 0927-7765

It is advisable to refer to the publisher's version if you intend to cite from the work. http://dx.doi.org/10.1016/j.colsurfb.2016.07.010

For more information about UCLan's research in this area go to http://www.uclan.ac.uk/researchgroups/ and search for < name of research Group $>$.

For information about Research generally at UCLan please go to http://www.uclan.ac.uk/research/

All outputs in CLoK are protected by Intellectual Property Rights law, including Copyright law. Copyright, IPR and Moral Rights for the works on this site are retained by the individual authors and/or other copyright owners. Terms and conditions for use of this material are defined in the policies page.

\section{CLoK}

Central Lancashire online Knowledge www.clok.uclan.ac.uk

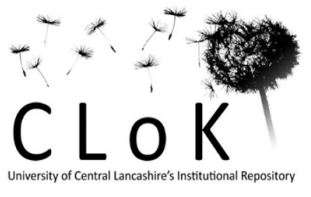




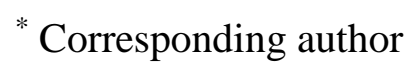

\section{a School of Phamay, Univesity of Bradfe, an}

a School of Pharmacy, University of Bradford, Bradford, BD7 1DP, UK.

${ }^{\mathrm{b}}$ Faculty of Pharmacy, University of Damascus, Damascus, Syria.

${ }^{\text {c }}$ Department of Pharmacy and Pharmacology, University of Bath, Bath BA2 7AY, UK.

${ }^{\mathrm{d}}$ Department of Pharmacy, University of Huddersfield, Queensgate, Huddersfield, HD1 3DH, UK.

Associate Professor in Pharmaceutical Technology

First name: Mohammad Amin

Family name: Mohammad

Phone: + 44 (0)1225 386797

Email: m.a.mohammad7@bradford.ac.uk

Postal address: Dr. Mohammad Amin Mohammad, School of Pharmacy, University of Bradford, Richmond Road, Bradford, BD7 1DP, UK.

Dr. Ian M. Grimsey, Senior Lecturer in Pharmaceutical Technology

Phone: +44 (0)1274 234754

Email: i.m.grimsey@bradford.ac.uk

School of Pharmacy, University of Bradford, Bradford BD7 1DP, UK

Prof. Robert T. Forbes, Professor of Biophysical Pharmaceutics

Phone: +44 (0)1274 234653

Email: r.t.forbes@bradford.ac.uk

School of Pharmacy, University of Bradford, Bradford BD7 1DP, UK

Dr. Ian S. Blagbrough

Phone: +44 (0) 1225386795

Email: prsisb@bath.ac.uk

Department of Pharmacy and Pharmacology, University of Bath, Bath BA2 7AY, UK.

Prof. Barbara R Conway,

Phone: +44 (0) 1484472347

Email: b.r.conway@hud.ac.uk

Department of Pharmacy, University of Huddersfield, Queensgate, Huddersfield, HD1 3DH, UK. 
ABSTRACT

47 Globular proteins are important both as therapeutic agents and excipients. However, their fragile 48 native conformations can be denatured during pharmaceutical processing, which leads to 49 modification of the surface energy of their powders and hence their performance. Lyophilized 50 powders of hen egg-white lysozyme and $\beta$-galactosidase from Aspergillus oryzae were used as 51 models to study the effects of mechanical denaturation on the surface energies of basic and acidic 52 protein powders, respectively. Their mechanical denaturation upon milling was confirmed by the 53 absence of their thermal unfolding transition phases and by the changes in their secondary and 54 tertiary structures. Inverse gas chromatography detected differences between both unprocessed 55 protein powders and the changes induced by their mechanical denaturation. The surfaces of the 56 acidic and basic protein powders were relatively basic, however the surface acidity of $\beta$ 57 galactosidase was higher than that of lysozyme. Also the surface of $\beta$-galactosidase powder had a 58 higher dispersive energy compared to lysozyme. The mechanical denaturation decreased the 59 dispersive energy and the basicity of the surfaces of both protein powders. The amino acid 60 composition and molecular conformation of the proteins explained the surface energy data

61 measured by inverse gas chromatography. The biological activity of mechanically denatured

62 protein powders can either be reversible (lysozyme) or irreversible ( $\beta$-galactosidase) upon 63 hydration. Our surface data can be exploited to understand and predict the performance of protein 64 powders within pharmaceutical dosage forms.

66 Keywords:

67 Protein denaturation; $\beta$-Galactosidase; Lysozyme; Conformational change; Inverse gas 68 chromatography; Surface free energy. 


\section{Introduction}

In the pharmaceutical field, there is considerable interest in the use of globular proteins for

72 their therapeutic effects. During pharmaceutical processes, protein powders are often subjected to

73 mechanical stresses. For example, milling has been used to prepare protein particles suitable for

74 pulmonary delivery and protein-loaded microparticles in industrial quantities [1,2]. The

75 mechanical stresses applied during the milling can partially or completely denature the proteins

76 and change their bulk properties [3]. In recent years, denatured globular proteins have found

77 extensive applications as excipients in pharmaceutical formulations [4,5]. Denatured globular

78 proteins have been used to prepare emulsion systems designed to enhance the absorption of

79 insoluble drugs and to form nanoparticles for drug delivery and targeting [4]. Globular proteins

80 have also been successfully used to formulate controlled drug delivery tablets, which delay drug

81 release in gastric conditions by forming a gel-layer stabilized by intermolecular-beta sheets of 82 denatured globular proteins [5].

83 Surface energies of powders are critical properties to be considered during formulation and

84 development of dosage forms in the pharmaceutical industry. Surface energy has significant effects

85 on pharmaceutical processes such as granulation, tableting, disintegration, dissolution, 86 dispersibility, immiscibility, wettability, adhesion, flowability, packing etc. Resultant data from

87 recent determination of surface energies have been used to reduce the time of formulation 88 development and enhance the quality of the final product [6-8].

89 The effect of the protein denaturation on their surface chemistry has been determined using 90 time-of-flight secondary ion mass spectrometry [9]. However, the effect of mechanical 91 denaturation on the surface energies of globular proteins has not been reported and these effects 
92 must be understood to exploit the full potential of globular proteins in pharmaceutical industry

93 both as therapeutic agents and excipients. Inverse gas chromatography (IGC) is a useful verified

94 tool for surface energy measurements [10]. IGC has been used to measure the surface free energy

95 of lyophilized protein particles, detecting lot-to-lot variations in the amorphous microstructure of 96 lyophilized protein formulations [11].

97 This paper aims to evaluate the effects of mechanical denaturation on the surface energies

98 of globular protein powders using IGC. $\beta$-Galactosidase is a hydrolytic enzyme that has been

99 widely investigated for potential applications in the food industry to improve sweetness, solubility,

100 flavor, and digestibility of dairy products. Preparations of $\beta$ galactosidases have also been

101 exploited for industrial, biotechnological, medical, and analytical applications [12]. Lysozyme is

102 a naturally occurring enzyme found in bodily secretions such as tears, saliva, and milk and has

103 been explored as a food preservative and pharmaceutical. The isoelectric points (pI) of $\beta$ -

104 galactosidase from Aspergillus oryzae and hen egg-white lysozyme are 4.6 and 11.3, and were

105 used as models of acidic and basic globular proteins, respectively [13]. Lyophilized powders of

106 these proteins were mechanically denatured by milling. Their surface energies before and after

107 denaturation were compared in order to understand how the surfaces of the globular protein 108 powders respond to the mechanical denaturation.

109

110 2. Materials and methods

111 2.1. Materials

112 Micrococcus lysodeikticus (Sigma-Aldrich), 2-nitrophenyl $\beta$-D-galacto pyranoside

113 (Sigma-Aldrich), lyophilized powders of $\beta$-galactosidase from A. oryzae (Sigma-Aldrich) and hen 114 egg-white lysozyme (Biozyme Laboratories, UK) were purchased as indicated. The purchased $\beta$ - 
115 galactosidase and lysozyme powders were considered to be unprocessed samples and named UNG

116 and UNL, respectively.

118 2.2. Preparation of mechanically denatured protein powders

119 Mechanically denatured powders of $\beta$-galactosidase and lysozyme were prepared by 120 manually milling. The milling was achieved by rotating a marble pestle over the powder within a 121 marble mortar at $\sim 45$ cycles per minute (cpm). Milling times of 60 min were enough to completely 122 denature the protein powders, and this was confirmed by differential scanning calorimetry (DSC)

123 [3]. The mechanically denatured powders of $\beta$-galactosidase and lysozyme were named DeG and 124 DeL, respectively. Three batches (2 g each batch) of the mechanically denatured powders were 125 prepared for each protein.

126

127 2.3. Microscopy

128 A Zeiss Axioplan2 polarizing microscope (Carl Zeiss Vision GmbH; Hallbergmoos, 129 Germany) was used to visualize the samples. The accompanying software (Axio Vision 4.2) was 130 then used to determine the projected area diameters of the powders.

132 2.4. Differential scanning calorimetry (DSC)

133 Differential scanning calorimetry (DSC) thermograms were obtained using a Perkin-Elmer 134 Series 7 DSC (Perkin-Elmer Ltd., Beaconsfield, UK). Samples (4-7 mg) were sealed in aluminium 135 pans. The escape of water was facilitated by making a pinhole in the lid prior to sealing. The 136 samples were equilibrated at $25^{\circ} \mathrm{C}$ and heated to $250{ }^{\circ} \mathrm{C}$ at a scan heating rate of $10^{\circ} \mathrm{C} / \mathrm{min}$ under 137 a flow of anhydrous nitrogen $(20 \mathrm{ml} / \mathrm{min})$. Each sample was analysed in triplicate. The temperature 
138 axis and cell constant of the DSC cell were calibrated with indium (10 mg, $99.999 \%$ pure, melting 139 point $156.60^{\circ} \mathrm{C}$, and heat of fusion $28.40 \mathrm{~J} / \mathrm{g}$ ).

\subsection{FT-Raman spectroscopy}

FT-Raman spectra of samples were recorded with a Bruker IFS66 optics system using a

143 Bruker FRA 106 Raman module. The excitation source was an Nd: YAG laser operating at 1064

$144 \mathrm{~nm}$ and a laser power of $50 \mathrm{~mW}$ was used. The FT-Raman module was equipped with a liquid

145 nitrogen cooled germanium diode detector with an extended spectrum band width covering the 146 wave number range $1800-450 \mathrm{~cm}^{-1}$. Samples were placed in stainless steel sample cups and 147 scanned 200 times with the resolution set at $8 \mathrm{~cm}^{-1}$. The observed band wave numbers were 148 calibrated against the internal laser frequency and are correct to better than $\pm 1 \mathrm{~cm}^{-1}$. The spectra 149 were corrected for instrument response. The experiments were run at a controlled room 150 temperature of $20 \pm 1^{\circ} \mathrm{C}$.

152 2.6. Enzymatic assay

153 The enzymatic activity of lysozyme samples was measured to determine the ability of

154 lysozyme to catalyze the hydrolysis of $\beta$-1,4-glycosidic linkages of cell-wall mucopolysaccharides

155 [14]. Lysozyme solution (30 $\mu \mathrm{l}, 0.05 \%$ in phosphate buffer, $\mathrm{pH}=5.2 ; 10 \mathrm{mM}$ ) was added to 156 Micrococcus lysodeikticus suspension (2.97 ml, $0.025 \%$ in phosphate buffer, $\mathrm{pH}=6.24 ; 66 \mathrm{mM}$ ).

157 The decrease in the absorbance at $450 \mathrm{~nm}$ was monitored by using a UV-Vis spectrophotometer 158 (PU 8700, Philips, UK). The activity was determined by measuring the decrease in the substrate 159 bacterial suspension concentration with time. Hence the slope of the reduction in light absorbance 160 at $450 \mathrm{~nm}$ against the time of 3 min, starting when the protein solutions were mixed with the 
161 substrate bacterial suspension, was considered to be the indicator of the lytic activity of lysozyme $162[15]$

The enzymatic activity of $\beta$-galactosidase samples was determined using a method relying

164 on the ability of $\beta$-galactosidase to hydrolyse the chromogenic substrate $o$-nitrophenyl $\beta$-D-galacto

165 pyranoside (ONPG) to $o$-nitrophenol [16]. The results were achieved by adding $20 \mu \mathrm{l}$ of protein 166 solution $(0.05 \mathrm{w} / \mathrm{v} \%$ in deionised water) to $4 \mathrm{ml}$ of the substrate solution $(0.665 \mathrm{mg} / \mathrm{ml})$ in a 167 phosphate buffer $(100 \mathrm{mM}$ and $\mathrm{pH}=7)$. The mixture then was incubated for $10 \mathrm{~min}$ in a water 168 bath at $30 \pm 1^{\circ} \mathrm{C}$. The absorbance at $\lambda=420 \mathrm{~nm}$ was measured to indicate the activity. using the following equation:

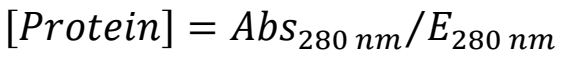

172 where [Protein] is the concentration of protein in the tested solution $\mathrm{w} / \mathrm{v} \%, A b s_{280 \mathrm{~nm}}$ is the 173 absorbance of the tested protein solution at $280 \mathrm{~nm}$, and $E_{280 \mathrm{~nm}}$ is the absorbance of protein

174 standard solution with concentration $0.05 \mathrm{w} / \mathrm{v} \%$. The concentrations of the solutions were diluted 175 to be about $0.05 \% \mathrm{w} / \mathrm{v}$ so as to give an absorbance value of less than 0.8 . The activities of all 176 samples were measured relative to that of a corresponding fresh sample, which was considered as 177 the standard solution. IGC experiments were performed using an inverse gas chromatography (IGC 2000,

181 Surface Measurement Systems Ltd., UK). A sample ( 500 mg) was packed into a pre-silanised 
182 glass column (300 $\mathrm{mm} \times 3 \mathrm{~mm}$ i.d.). Three columns of each sample were analysed at $30{ }^{\circ} \mathrm{C}$ (the

183 lowest temperature at which the IGC experiments can be performed to avoid thermal stress) and

184 zero relative humidity, using anhydrous helium gas as the carrier. A series of n-alkanes (n-hexane

185 to n-nonane) in addition to chloroform, as a monopolar electron acceptor probe $\left(l_{+}\right)$, and ethyl

186 acetate, as a monopolar donor acceptor probe $\left(l_{-}\right)$, were injected through the columns at the infinite

187 dilution region. Their retention times followed from detection using a flame ionization detector 188 (FID).

\subsubsection{Surface energy calculations}

191 Our published methods were used to calculate the surface energies and verify their 192 accuracy [17-19]. These methods describe the surface properties using the dispersive retention 193 factor $\left(K_{C H_{2}}^{a}\right)$, the electron acceptor retention factor $\left(K_{l+}^{a}\right)$, and the electron donor retention factor $194\left(K_{l-}^{a}\right)$, which are calculated using the retention times of probes:

$$
\ln \left(\mathrm{t}_{\mathrm{r}}-\mathrm{t}_{0}\right)=\left(\ln K_{C H_{2}}^{a}\right) \mathrm{n}+\mathrm{C}
$$

196 where $n$ is the carbon number of the homologous $n$-alkanes, $t_{r}$ and $t_{0}$ are the retention times of the 197 n-alkanes and a non-adsorbing marker, respectively, $\mathrm{K}_{\mathrm{CH}_{2}}^{a}$ is the dispersive retention factor of the 198 analysed powder and $\mathrm{C}$ is a constant. The linear regression statistics of equation 2 generate the 199 value of $\mathrm{t}_{0}$ which gives its best linear fit. The slope of the equation 2 gives the value of $\mathrm{K}_{\mathrm{CH}_{2}}^{a}$.

$$
\begin{aligned}
& K_{l+}^{a}=t_{n l+} / t_{n l+, \text { ref }} \\
& K_{l-}^{a}=t_{n l-} / t_{n l-, r e f}
\end{aligned}
$$


202 where $t_{n l+}$ and $t_{n l+, \text { ref }}$ are the retention time of $l_{+}$and its theoretical n-alkane reference, 203 respectively, $t_{n l-}$ and $t_{n l-, \text { ref }}$ are the retention time of $l_{-}$and its theoretical n-alkane reference, 204 respectively.

$$
\ln t_{n l+, r e f}=\ln t_{n C i}+\left(\frac{\alpha_{l+}\left(\gamma_{l+}^{d}\right)^{0.5}-\alpha_{C i}\left(\gamma_{C i}^{d}\right)^{0.5}}{\alpha_{C H_{2}}\left(\gamma_{C H_{2}}\right)^{0.5}}\right) \ln K_{C H_{2}}^{a}
$$

$$
\ln t_{n l-, r e f}=\ln t_{n C i}+\left(\frac{\alpha_{l-}\left(\gamma_{l-}^{d}\right)^{0.5}-\alpha_{C i}\left(\gamma_{C i}^{d}\right)^{0.5}}{\alpha_{C H_{2}}\left(\gamma_{C H_{2}}\right)^{0.5}}\right) \ln K_{C H_{2}}^{a}
$$

207 where $\alpha_{\mathrm{CH}_{2}}$ and $\gamma_{\mathrm{CH}_{2}}, \alpha_{C i}$ and $\gamma_{C i}^{d}, \alpha_{l+}$ and $\gamma_{l+}^{d}$, and $\alpha_{l-}$ and $\gamma_{l-}^{d}$ are the cross-sectional area and

208 the dispersive free energy of a methylene group, an n-alkane, $l_{+}$and $l_{-}$, respectively. $t_{n C i}$ is the 209 retention time of the n-alkane.

210 The retention factors are then used to calculate the surface dispersive $\left(\gamma_{\mathrm{s}}^{\mathrm{d}}\right)$, electron donor $\left(\gamma_{\mathrm{s}}^{-}\right)$and 211 electron acceptor $\left(\gamma_{\mathrm{s}}^{+}\right)$components of the powders:

$$
\begin{aligned}
& \gamma_{\mathrm{s}}^{\mathrm{d}}=\frac{0.477\left(\mathrm{~T} \ln \mathrm{K}_{\mathrm{CH}}\right)^{2}}{\left(\alpha_{C \mathrm{CH}_{2}}\right)^{2} \gamma_{\mathrm{CH}_{2}}} \mathrm{~mJ} \cdot \mathrm{m}^{-2} \\
& \gamma_{\mathrm{s}}^{-}=\frac{0.477\left(\mathrm{~T} \ln K_{l+}^{a}\right)^{2}}{\left(\alpha_{l+}\right)^{2} \gamma_{l+}^{+}} \mathrm{mJ} \cdot \mathrm{m}^{-2} \\
& \gamma_{\mathrm{s}}^{+}=\frac{0.477\left(\mathrm{~T} \ln K_{l-}^{a}\right)^{2}}{\left(\alpha_{l-}\right)^{2} \gamma_{l-}^{-}} \mathrm{mJ} \cdot \mathrm{m}^{-2}
\end{aligned}
$$

215 where $\gamma_{l_{+}}^{+}$is the electron acceptor component of $l_{+}$and $\gamma_{l_{-}}^{-}$is the electron donor component of

$216 l_{-}$. The units of $\alpha$ are $\AA^{2}$ and of $\gamma$ are $\mathrm{mJ}^{-2} \mathrm{~m}^{-2}$ in all equations.

217 The parameters of $\mathrm{CH}_{2}$ are calculated from the following equation:

$$
\left(\alpha_{\mathrm{CH}_{2}}\right)^{2} \gamma_{\mathrm{CH}_{2}}=-1.869 \mathrm{~T}+1867.194 \AA^{4} \cdot \mathrm{mJ} \cdot \mathrm{m}^{-2}
$$


$\left.22119.20 \mathrm{~mJ} / \mathrm{m}^{2}, \gamma_{l-}^{d}=19.60 \mathrm{~mJ} / \mathrm{m}^{2}, \alpha_{l-}=48.0 \AA^{2}\right)$ and for chloroform $\left(\gamma_{l+}^{+}=3.80 \mathrm{~mJ} / \mathrm{m}^{2}, \gamma_{l+}^{d}=25.90\right.$

$\left.222 \mathrm{~mJ} / \mathrm{m}^{2}, \alpha_{l+}=44.0 \AA^{2}\right)[17,22]$. However, using any other different reported numbers will not 223 change the findings of the comparison.

224 The percentage coefficient of variation of $\ln K_{\mathrm{CH}_{2}}^{a}\left(\% \mathrm{CV}_{\ln \mathrm{C}_{C \mathrm{H}_{2}}^{a}}\right)$ is the indicator of the 225 accuracy of the surface energy measurements. The error of the slope of the equation $2\left(S D_{\ln K_{C H_{2}}^{a}}\right)$ 226 is used to calculate $\% C V_{\ln K_{C H_{2}}^{a}}$ :

$$
\% C V_{\ln K_{C H_{2}}^{a}}^{a}=\left(S D_{\ln K_{C H_{2}}^{a}} / \ln K_{C H_{2}}^{a}\right) \times 100
$$

$228 \% C V_{\ln K_{\mathrm{CH}_{2}}^{a}}$ should be less than $0.7 \%$ to accept the accuracy of the measurement. \%CV $V_{\ln K_{\mathrm{CH}_{2}}^{a}}$ is then

229 used to calculate the uncertainty range of $\gamma_{\mathrm{s}}^{\mathrm{d}}$ :

$230 \quad$ Uncertainty Range of $\gamma_{\mathrm{s}}^{\mathrm{d}}=\left[\left(\frac{100 \times \gamma_{\mathrm{s}}^{\mathrm{d}}}{100+7.5 \% C V_{\ln K_{C H_{2}}^{a}}}\right)\right.$ to $\left.\left(\frac{100 \times \gamma_{\mathrm{s}}^{\mathrm{d}}}{100-7.5 \% C V_{\ln K_{C H_{2}}^{a}}}\right)\right]$

\section{3. Results and discussion}

233 3.1. Microscopy

The photomicrographs of UNL, UNG, DeL, and DeG powders show that they had project235 area diameters of $\sim 4 \mu \mathrm{m}$ (Fig. S1), $2.5 \mu \mathrm{m}$ (Fig. S2), 1.5 $\mu \mathrm{m}$ (Fig. S3), and 1.5 $\mu \mathrm{m}$ (Fig. S4), 236 respectively. The particle sizes of the original powders were below $5 \mu \mathrm{m}$. Therefore, the attrition 237 mechanism was dominant during milling, and so the same original faces did not change [3].

\subsection{Differential scanning calorimetry (DSC)}

For both proteins, DSC thermograms exhibited broad peaks ranging from $\sim 30$ to $\sim 140{ }^{\circ} \mathrm{C}$

241 (Figure 1). These peaks are due to water removal, and their areas depend on water residues in the 
242 powders [3]. The enthalpy of the water evaporation peak was $118 \pm 11,124 \pm 6,114 \pm 9$ and $130 \pm 8$

$243 \mathrm{~J} / \mathrm{g}$ for UNL, UNG, DeL, and DeG, respectively, and did not significantly change after milling (t-

244 test: $\mathrm{P}<0.05)$. The protein powders exchange water with the surrounding air depending on

245 conditions of temperature, relative humidity and exposure time. Therefore, the conditions used

246 during milling did not change the water content of the powders. Also Figure 1 shows that the

247 unprocessed proteins unfolded and a peak was detected at their apparent denaturation

248 temperatures, which varied according to the protein. DSC thermograms of UNL displayed one

249 denaturation peak at $\sim 201{ }^{\circ} \mathrm{C}$, but UNG displayed two denaturation peaks at $\sim 176{ }^{\circ} \mathrm{C}$ and $\sim 212$

$250{ }^{\circ} \mathrm{C}$.

251

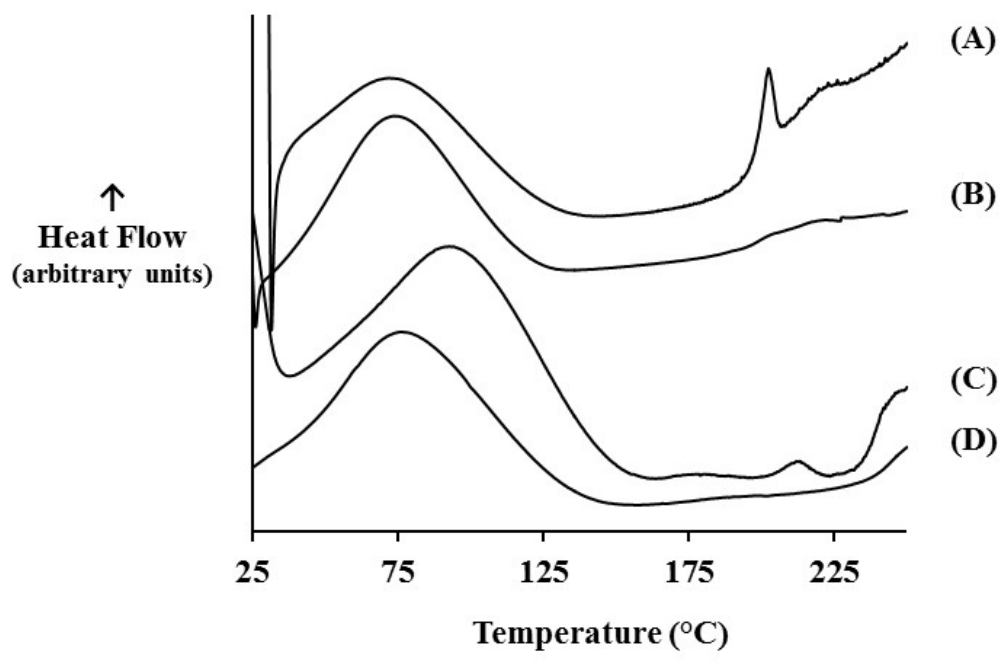

Fig. 1. Example DSC thermograms of protein powders (A) unprocessed lysozyme, (B) mechanically denatured lysozyme, (C) unprocessed $\beta$-galactosidase, (D) mechanically denatured $\beta$-galactosidase. Conditions: samples heated from 25 to $250{ }^{\circ} \mathrm{C}$; heating rate: 10 ${ }^{\circ} \mathrm{C} / \mathrm{min}$. 
255 manner and so exhibits an all-or-none thermal unfolding transition, $\beta$-galactosidase goes through

256 a non-two state thermal unfolding transition resulting in two peaks [26,27]. The unfolding 257 transition peaks were completely lost after mechanical denaturation. Hence there was no peak at $258 \sim 201{ }^{\circ} \mathrm{C}$ for the milled lysozyme samples and neither were there peaks at $\sim 176{ }^{\circ} \mathrm{C}$ and $\sim 212{ }^{\circ} \mathrm{C}$ 259 for the milled $\beta$-galactosidase. The complete disappearance of the unfolding transition peak from 260 the DSC thermogram indicates the total transition of the protein from its folded state to its unfolded 261 state [3].

262

263 3.3. FT-Raman study

264 Raman spectroscopy was used to compare the molecular conformation of protein powders 265 before and after mechanical denaturation. The band at $\sim 1450 \mathrm{~cm}^{-1}$ indicates the $\mathrm{CH}$ bending 266 vibrations of aliphatic side chains, and its intensity and position are unaffected by changes induced 267 in protein structure after dehydration or applying different stresses [28]. Therefore, it was used as 268 an internal intensity standard to normalize Raman spectra before comparison (Figures 2A and 3A). 269 The vibration modes of amide I ( $\mathrm{C}=\mathrm{O}$ stretch) from 1580 to $1720 \mathrm{~cm}^{-1}$ (Figures 2B and 3B) and 270 amide III (N-H in-plane bend + C-N stretch) from 1250-1330 $\mathrm{cm}^{-1}$ (Figures 2C and 3C) 271 demonstrated the secondary structure of $\beta$-galactosidase and lysozyme, respectively. The spectra 272 of the denatured samples show that the modes of the amide I upshifted and broadened for both 273 proteins, and the mode of the amide III intensified and downshifted, especially for lysozyme, but 274 there was no change in the mode of amide III for $\beta$-galactosidase. These changes indicated the 275 transformation of $\alpha$-helix content to $\beta$-sheets or a disordered structure which enhances the tendency 276 of proteins to aggregate [3,29]. While $\beta$-galactosidase is a beta-type protein containing mainly $\beta$ - 
277 sheet structure and only 5\% $\alpha$-helix [30], the secondary structure of lysozyme consists of $30 \% \alpha$ -

278 helix [31]. This explains why no changes in the amide III of $\beta$-galactosidase were observed.

279 The aggregation of denatured proteins combined with changes in the vibration modes of 280 the aromatic residues at $\sim 1550 \mathrm{~cm}^{-1}$ in $\beta$-galactosidase (Figure 2D), $1320-1380 \mathrm{~cm}^{-1}$ in lysozyme 281 (Figure 3D) and 800-900 $\mathrm{cm}^{-1}$ in both proteins (Figures 2E and 3E). These changes in the vibration 282 modes of the aromatic residues result from the changes in their micro-environment after 283 denaturation because of their roles in the denaturation processes [29,32]. The aggregates of 284 denatured protein molecules are formed via $\pi$-stacking interactions of the aromatic residues [33].

\section{(A)}

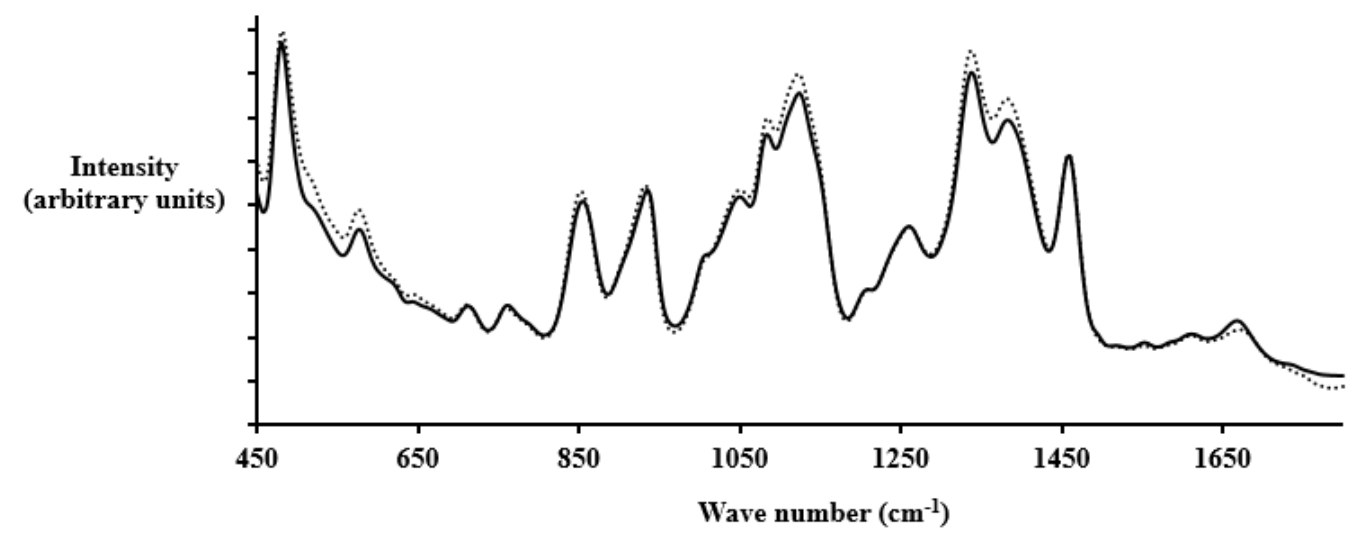

(B)

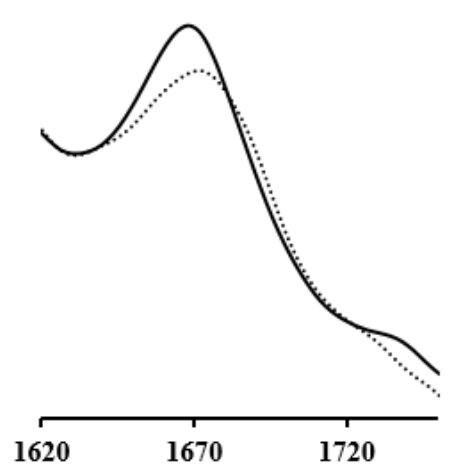

(D)
(C)

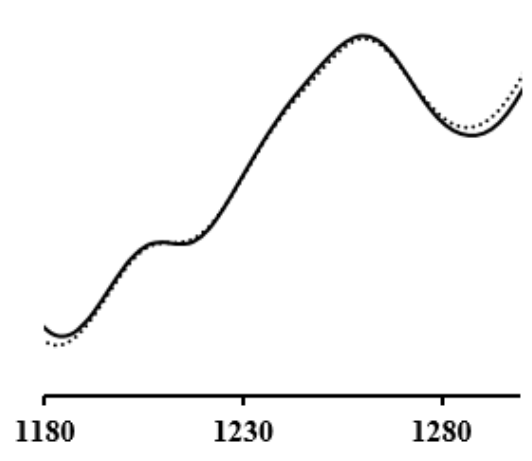

(E) 

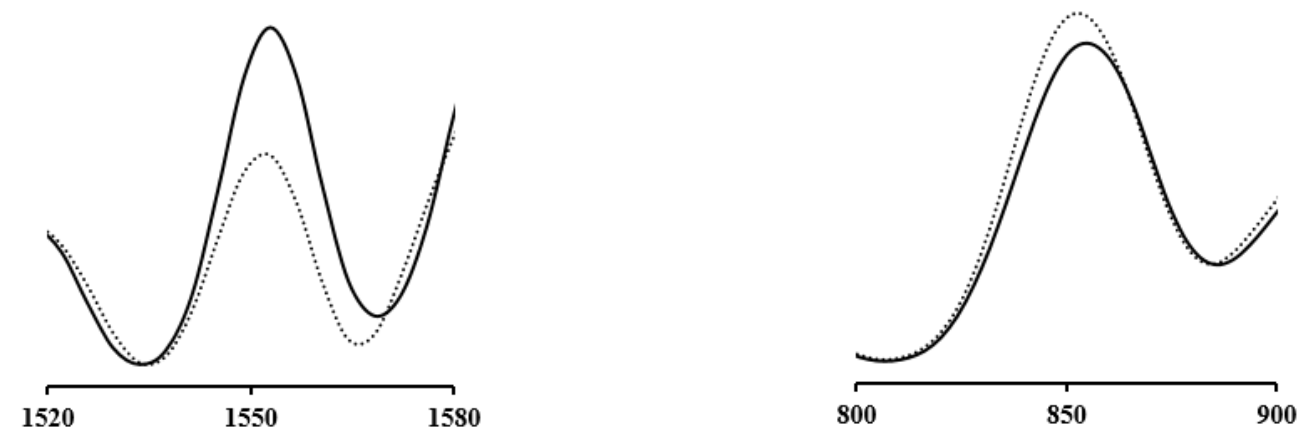

Fig. 2. FT-Raman spectra of $\beta$-galactosidase powders, the unprocessed powders (solid lines) and the mechanically denatured powders (dotted lines). Vibration modes of secondary structure are (B) amide I and (C) amide III. Vibration modes of tertiary structure are (D) for Trp and (E) for Trp and Tyr. The spectra were normalized using the methylene deformation mode at $\sim 1450 \mathrm{~cm}^{-1}$ as an

(A)

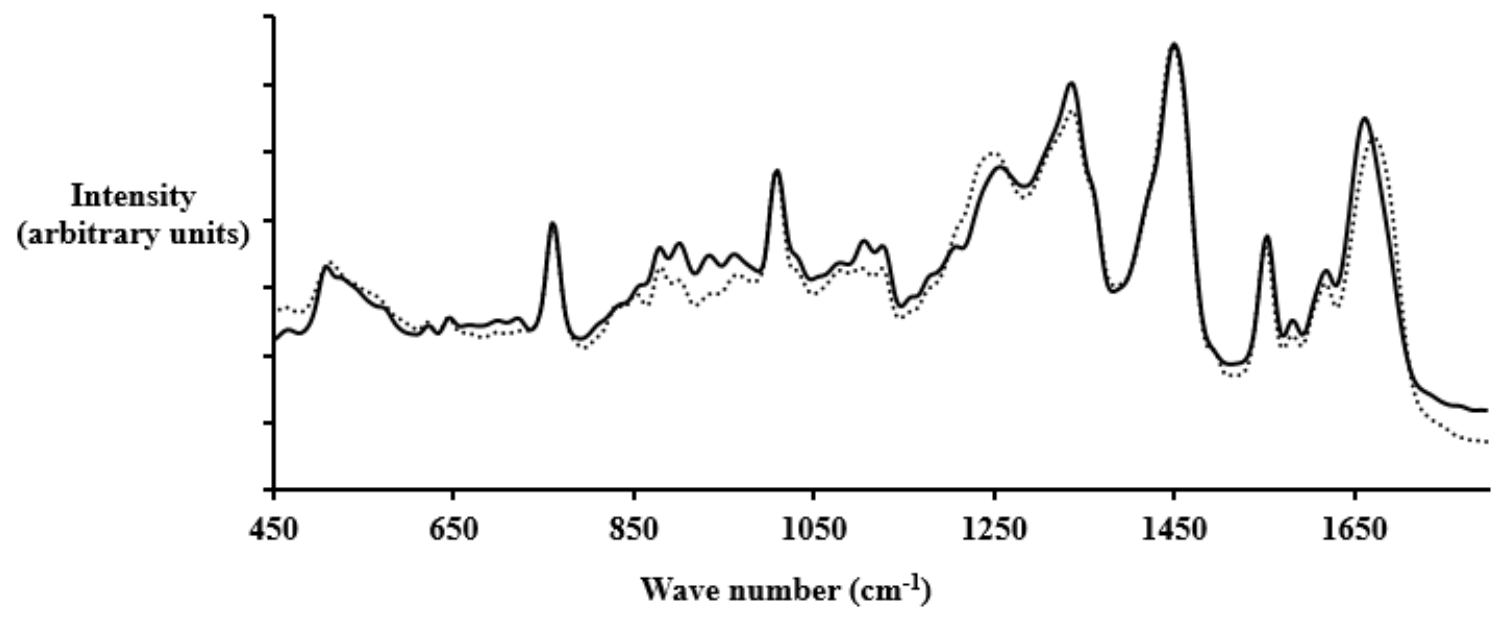

(B)

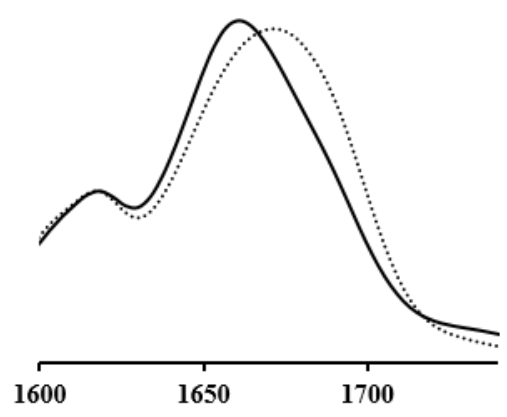

(D)
(C)

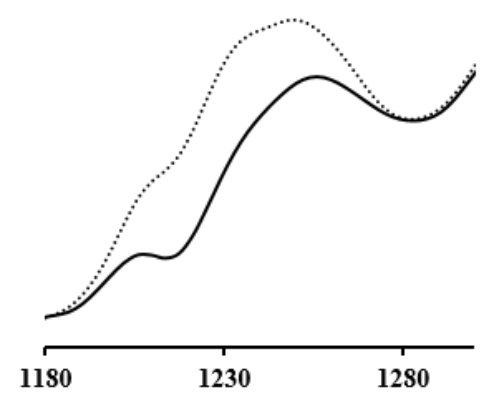

(E) 

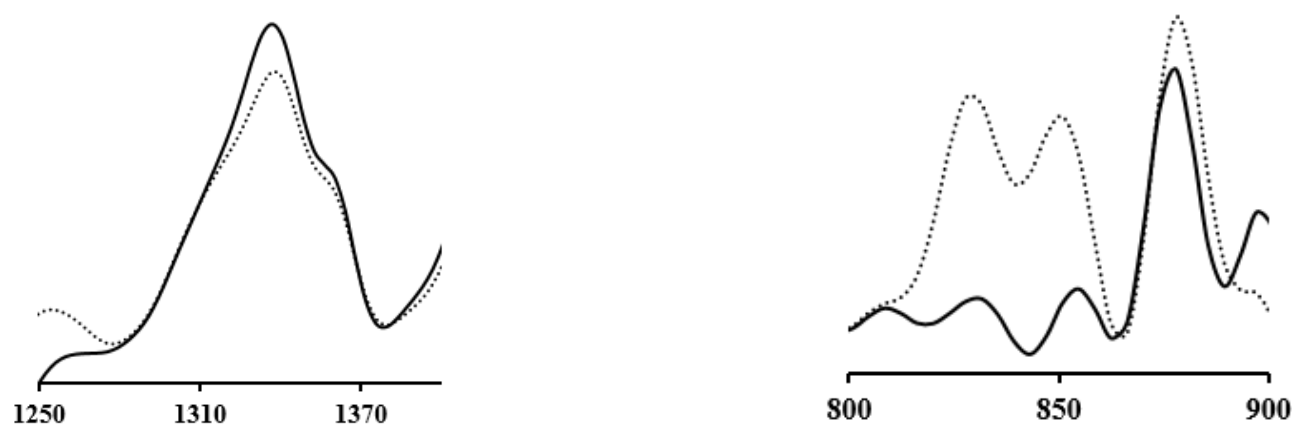

291 Fig. 3. FT-Raman spectra of lysozyme powders, the unprocessed powders (solid lines) and the mechanically denatured powders (dotted lines). Vibration modes of secondary structure are (B) amide I and (C) amide III. Vibration modes of tertiary structure are (D) for Trp and (E) for Trp and Tyr. The spectra were normalized using the methylene deformation mode at $\sim 1450 \mathrm{~cm}^{-1}$ as 295 an internal intensity standard.

\subsection{Enzymatic assay}

Therapeutic proteins may rapidly denature and lose their enzymatic activity. The structure

299 changes detected using FT-Raman and the absence of Tm detected by DSC have been used to 300 monitor the denaturation of proteins, and the results of Raman and DSC are linked to the results 301 of enzymatic activity [34]. Our DSC and Raman results confirmed the denaturation of both 302 proteins studied. The enzymatic assay showed that the mechanically denatured $\beta$-galactosidase 303 samples (DeG) demonstrated no enzymatic activity (Figure 4). However, the mechanically 304 denatured lysozyme samples (DeL) maintained full enzymatic activity when compared to an 305 unprocessed sample (t-test: $P<0.05)$ (Figure 4). This is due to the ability of denatured lysozyme 306 to refold upon dissolution in aqueous media and thus the biological activity of lysozyme is fully 307 recovered following dissolution [3.35]. 


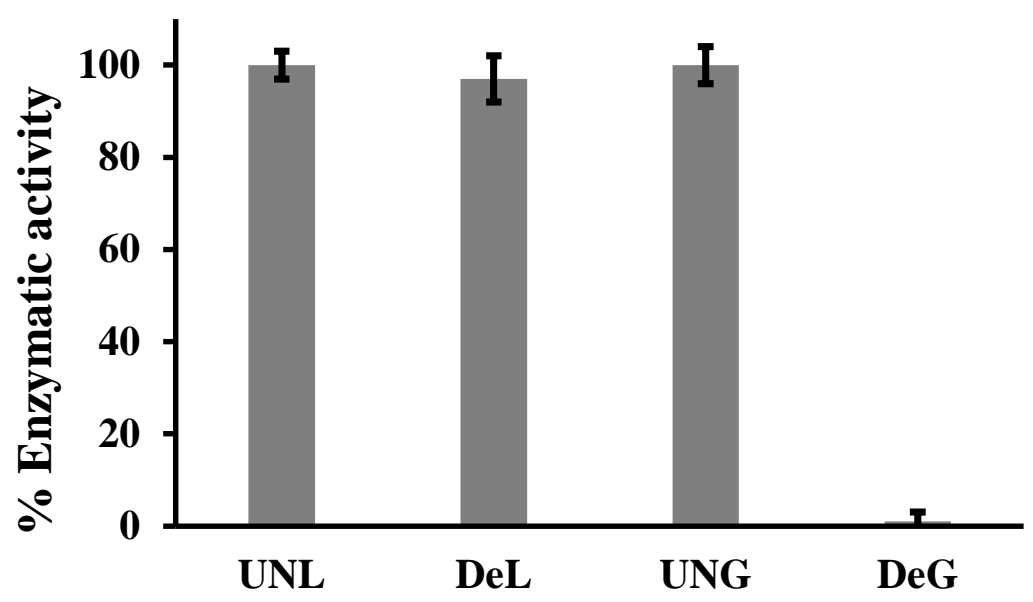

\section{Fig. 4. Enzymatic activity of the unprocessed powders and the mechanically} denatured powders of lysozyme and $\beta$-galactosidase.

313 3.5. Surface free energy

314 The IGC results (Table 1) confirm the acceptable accuracy of the IGC experiments 315 considered in this work with $\% C V_{\ln _{C H}^{a}}^{a}$ values of less than 0.7\% [18]. IGC data for the unprocessed 316 powders demonstrated the differences in the surface free energy between $\beta$-galactosidase (an 317 acidic protein) and lysozyme (a basic protein). UNG had higher $\gamma_{\mathrm{s}}^{\mathrm{d}}$ compared to UNL because the 318 uncertainty ranges of $\gamma_{\mathrm{s}}^{\mathrm{d}}$ of UNG and UNL did not overlap for the three columns [18]. The surface 319 acidity $\left(\gamma_{\mathrm{s}}^{+}\right)$and the surface basicity $\left(\gamma_{\mathrm{s}}^{-}\right)$of UNG were significantly different from their 320 counterparts of UNL (t-test: $P<0.05$ ). The average of $\gamma_{\mathrm{s}}^{+}$was $16.2 \pm 0.2$ and $12.4 \pm 0.1 \mathrm{~mJ}^{-2} \mathrm{~m}^{-2}$ and 321 the average of $\gamma_{\mathrm{s}}^{-}$was $5.5 \pm 0.2$ and $10.5 \pm 0.6 \mathrm{~mJ} . \mathrm{m}^{-2}$ for UNG and UNL, respectively. This proves 322 that UNG, chosen as a model for acidic proteins, has higher surface acidity and lower surface 323 basicity compared to selected basic protein, UNL.

325 Table 1. The surface energies $\left(\gamma_{\mathrm{s}}^{\mathrm{d}}, \gamma_{\mathrm{s}}^{+}\right.$and $\left.\gamma_{\mathrm{s}}^{-}\right)$and retention factors $\left(K_{C H_{2}}^{a}, K_{l+}^{a}\right.$ and $\left.K_{l-}^{a}\right)$ of the 326 lyophilized lysozyme powder (UNL), the lyophilized $\beta$-galactosidase powder (UNG), the 
327 mechanically denatured lyophilized lysozyme powder (DeL) and the mechanically denatured 328 lyophilized $\beta$-galactosidase powder (DeG).

\begin{tabular}{|c|c|c|c|c|c|c|c|c|c|}
\hline Material & Column & $K_{\mathrm{CH}_{2}}^{a}$ & $K_{l+}^{a}$ & $K_{l-}^{a}$ & $\% C V_{\ln K_{C H_{2}}^{a}}$ & $\begin{array}{c}\gamma_{\mathrm{s}}^{\mathrm{d}} \\
\mathrm{mJ} \cdot \mathrm{m}^{-2}\end{array}$ & $\begin{array}{l}\text { Uncertainty Range of } \gamma_{\mathrm{s}}^{\mathrm{d}} \\
\mathrm{mJ}^{-\mathrm{m}^{-2}}\end{array}$ & $\begin{array}{c}\gamma_{\mathrm{s}}^{+} \\
\mathrm{mJ} . \mathrm{m}^{-2}\end{array}$ & $\begin{array}{c}\gamma_{\mathrm{s}}^{-} \\
\mathrm{mJ} \cdot \mathrm{m}^{-2}\end{array}$ \\
\hline UNL & 1 & 3.099 & 3.725 & 34.572 & 0.144 & 43.1 & $41.9-44.4$ & 12.4 & 10.3 \\
\hline UNL & 2 & 3.095 & 3.677 & 34.668 & 0.094 & 43.0 & $42.2-43.9$ & 12.5 & 10.1 \\
\hline UNL & 3 & 3.089 & 3.944 & 33.704 & 0.077 & 42.9 & $42.2-43.6$ & 12.3 & 11.2 \\
\hline DeL & 1 & 2.937 & 2.781 & 33.948 & 0.127 & 39.1 & $38.1-40.2$ & 12.3 & 6.2 \\
\hline DeL & 2 & 2.965 & 2.742 & 31.928 & 0.147 & 39.8 & $38.7-41.0$ & 11.9 & 6.1 \\
\hline DeL & 3 & 2.944 & 2.801 & 31.826 & 0.117 & 39.3 & $38.4-40.3$ & 11.9 & 6.3 \\
\hline UNG & 1 & 3.235 & 2.542 & 55.641 & 0.141 & 46.5 & $45.1-47.8$ & 16.0 & 5.2 \\
\hline UNG & 2 & 3.222 & 2.640 & 58.508 & 0.076 & 46.1 & $45.4-46.9$ & 16.4 & 5.6 \\
\hline UNG & 3 & 3.228 & 2.625 & 56.028 & 0.158 & 46.3 & $44.8-47.9$ & 16.1 & 5.6 \\
\hline DeG & 1 & 2.926 & 1.980 & 43.387 & 0.205 & 38.9 & $37.3-40.6$ & 14.1 & 2.8 \\
\hline DeG & 2 & 2.958 & 1.829 & 41.065 & 0.160 & 39.7 & $38.4-41.0$ & 13.7 & 2.2 \\
\hline DeG & 3 & 2.948 & 1.841 & 39.710 & 0.221 & 39.4 & $37.7-41.3$ & 13.4 & 2.2 \\
\hline
\end{tabular}

331 pI, the higher the basicity of the molecule [36]. The isoelectric points (pI) of the $\beta$-galactosidase

332 and lysozyme used are 4.6 and 11.3, respectively [13]. The molecule of $\beta$-galactosidase contains

$333 \sim 11 \mathrm{w} / \mathrm{w} \%$ basic amino acids (histidine, lysine, and arginine) and $\sim 22 \mathrm{w} / \mathrm{w} \%$ acidic (aspartic acid

334 and glutamic acid) residues [37], i.e., approximately double the number of acidic groups compared

335 to basic. Conversely the lysozyme contains $\sim 18 \mathrm{w} / \mathrm{w} \%$ and $\sim 7 \mathrm{w} / \mathrm{w} \%$ basic (histidine, lysine, and

336 arginine) and acidic (aspartic acid and glutamic acid) residues, respectively [38]. Detailed

337 information regarding the structures of $\beta$-galactosidase and lysozyme can be found in $[37,38]$.

338 However, this is not the only determinant of energy as the surfaces of both the acidic (UNG) and

339 basic (UNL) protein powders were relatively basic (the values of $\gamma_{\mathrm{s}}^{+}>\gamma_{\mathrm{s}}^{-}$). Therefore to explain

340 our results further, the interaction of protein molecules with surfaces and interfaces, during

341 preparation using lyophilization technique, must be considered.

As protein molecules are surface active containing both polar and nonpolar groups, they

343 tend to adsorb to interfaces via hydrophobic interactions (London), coulombs (electrostatic) and/or 
344 hydrogen bonding, and they reorient their surfaces to the parts which give the optimum attractive 345 force and the most stable state (minimum energy) with a substrate or an interface [39]. Upon 346 lyophilization, protein molecules adsorb to the formed ice via hydrophobic residues but not via 347 hydrophilic residues, and this gives support to the hypothesis that the interaction of proteins with 348 ice involves appreciable hydrophobic interactions [40]. The hydrophobic regions in protein 349 molecules interact spontaneously with the ice faces by an entropy driving force [41]. The rich 350 electron rings of aromatic residues orient so that the ring structures lie flat with the interface in 351 order to maximize the interaction at interfaces and lower the Gibbs free energy of the system [42]. 352 Therefore, lyophilized protein particles expose the rich electron rings of the aromatic residues on 353 their surfaces. Aromatic groups, via their $\pi$ electrons, which are considered nucleophilic, can form 354 hydrogen bonds with chemical groups (acidic polar probes) being the hydrogen donors [43]. 355 Therefore, exposing these rings to surfaces relatively increases their basicity compared to their 356 acidity irrespective of the acidic or basic nature of the proteins themselves. Also the ring structures 357 can participate in raising the dispersive surface energy via London interactions due to their high 358 polarizability [43]. The aromatic residues (tryptophan, tyrosine, and phenylalanine) make up $35916 \% \mathrm{w} / \mathrm{w}$ of the $\beta$-galactosidase molecules and $14 \% \mathrm{w} / \mathrm{w}$ of the lysozyme molecules $[37,38]$. This

360 explains the higher values of $\gamma_{\mathrm{s}}^{\mathrm{d}}$ of $\beta$-galactosidase compared to lysozyme, prior to mechanical 361 denaturation.

362 UNG was more acidic than UNL. The size and the shape of the molecule can also influence 363 orientation. UNG is larger than UNL, with a globular shape and when some of the chemical groups 364 are preferably exposed to a surface (energetically or entropically), this will expose not only those 365 specific groups but also other closely associated groups which will vary in nature from one protein 
to another.. Thus, the surfaces of the acidic protein ( $\beta$-galactosidase) were more acidic compared

367 to the basic protein (lysozyme).

368 Table 1 shows that mechanical denaturation decreased the dispersive free energy and the basicity

369 of the surfaces of protein powders, irrespective of the nature of the protein (acidic or basic).

370 Usually milling induces an increase in the dispersive energy due to the generation of surface

371 amorphous regions or/and creation of higher energy crystal faces because of particle

372 fracture/breakage, thus the surface acidity and basicity change according to the formation of new

373 faces and regions $[44,45]$. However, in our case, due to lyophilization, the protein powders are

374 amorphous with particle sizes below $5 \mu \mathrm{m}$. Therefore, there would be no further size reduction by

375 fracture mechanisms because of brittle ductile transition [3]. Therefore, the denatured protein

376 powders were produced by milling where the attrition mechanism was dominant and so the same

377 original faces did not change. During milling, the extensive mechanical energy completely

378 denatured the protein molecules as confirmed by DSC and Raman results. This denaturation led to

379 aggregation of the protein molecules via non-covalent interactions through $\pi$-stacking interactions

380 [33]. This caused a loss of the aromatic groups, which are rich in $\pi$ electrons, from the surfaces.

381 Therefore, a decrease in the Van der Waals interactions, a major contributor to dispersive energy

382 and nucleophilicity (basicity) occurred, and so $\gamma_{\mathrm{s}}^{\mathrm{d}}$ and $\gamma_{\mathrm{s}}^{-}$decreased after denaturation for both

383 proteins. Also this loss of aromatic residues from the surface of the denatured powders renders $\gamma_{\mathrm{s}}^{\mathrm{d}}$

384 similar for both proteins. This is further evidence that the exposed aromatic residues raise the $\gamma_{\mathrm{s}}^{\mathrm{d}}$

385 as outlined previously. The Raman spectroscopic results confirmed that the aromatic residues were

386 involved in the denaturation processes, therefore, supporting the findings and our interpretation of 387 the IGC studies.

388 4. Conclusions 
390 acid compositions. The absence of the thermal unfolding transition phase for the proteins

391 (lysozyme and $\beta$-galactosidase) and the changes in the conformation of the back-bone and side 392 chains confirmed that the mechanical milling process caused denaturation of the protein powders, 393 and this denaturation could potentially be reversible in solution. The acidic protein powder ( $\beta$ 394 galactosidase) had higher surface acidity $\left(\gamma_{\mathrm{s}}^{+}\right)$and lower surface basicity $\left(\gamma_{\mathrm{s}}^{-}\right)$compared to the 395 basic protein powder (lysozyme). However, both protein powders had relatively basic surfaces due 396 to the rich electron rings of the aromatic residues which are nucleophilic. During mechanical 397 denaturation, these rings tend to associate through $\pi$-stacking interactions and are thus concealed 398 from the surface. Their removal reduced $\gamma_{\mathrm{s}}^{-}$and $\gamma_{\mathrm{s}}^{\mathrm{d}}$ of the surfaces of both protein powders, and 399 thereby yielded similar $\gamma_{\mathrm{s}}^{\mathrm{d}}$ for the surfaces of both proteins.

\section{Acknowledgements}

402 MAM gratefully acknowledges CARA (Stephen Wordsworth and Ryan Mundy) the Universities 403 of Bath and Bradford for providing academic fellowships.

\section{Supplementary data}

406 Supplementary data associated with this article can be found, in the online version, at 407 http://dx.doi.org/XXXX.

408

409

410

411

412

413

\section{References}


414 [1] H. Hoyer, W. Schlocker, K. Krum, A. Bernkop-Schnürch, Eur. J. Pharm. Biopharm. 69 (2008) 415476.

416 [2] W. Schlocker, S. Gschliesser, A. Bernkop-Schnürch, Eur. J. Pharm. Biopharm. 62 (2006) 260.

417 [3] M.A. Mohammad, I.M. Grimsey, R.T. Forbes, J. Pharm. Biomed. Anal. 114 (2015) 176.

418 [4] W. He, K. Yang, L. Fan, Y. Lv, Z. Jin, S. Zhu, C. Qin, Y. Wang, L. Yin, Int. J. Pharm. 495 419 (2015) 9.

420 [5] R. Caillard, M. Subirade, Int. J. Pharm. 437 (2012) 130.

421 [6] V. Karde, C. Ghoroi, Int. J. Pharm. 475 (2014) 351.

422 [7] X. Han, L. Jallo, D. To, C. Ghoroi, R. Davé, J. Pharm. Sci. 102 (2013) 2282.

423 [8] D. Cline, R. Dalby, Pharm. Res. 19 (2002) 1274.

424 [9] M.S. Killian, H.M. Krebs, P. Schmuki, Langmuir 27 (2011) 7510.

425 [10] O. Planinsek, A. Trojak, S. Srcic, Int. J. Pharm. 221 (2001) 211.

426 [11] Y. Hirakura, H. Yamaguchi, M. Mizuno, H. Miyanishi, S. Ueda, S. Kitamura, Int. J. Pharm. 340 (2007) 34.

[12] Q. Husain, Crit. Rev. Biotechnol. 30 (2010) 41.

[13] M. Ospinal-Jiménez, D.C. Pozzo, Langmuir 28 (2012) 17749.

[14] R.R. Haj-Ahmad, A.A. Elkordy, C.S. Chaw, A. Moore, Eur. J. Pharm. Sci. 49 (2013) 519.

[15] S. Chakraborti, T. Chatterjee, P. Joshi, A. Poddar, B. Bhattacharyya, S.P. Singh, V. Gupta, P. Chakrabarti, Langmuir 26 (2010) 3506.

[16] R.E. Hamlin, T.L. Dayton, L.E. Johnson, M.S. Johal, Langmuir 23 (2007) 4432.

[17] M.A. Mohammad, J. Chromatogr. A 1318 (2013) 270.

[18] M.A. Mohammad, J. Chromatogr. A 1399 (2015) 88.

[19] M.A. Mohammad, J. Chromatogr. A 1408 (2015) 267.

[20] B. Shi, D. Qi, J. Chromatogr. A 1231 (2012) 73.

[21] C. Della Volpe, D. Maniglio, M. Brugnara, S. Siboni, M. Morra, J. Colloid Interface Sci. 271 (2004) 434.

[22] S.C. Das, I. Larson, D.A. Morton, P.J. Stewart, Langmuir 27 (2011) 521.

[23] C.D. Volpe, S. Siboni, J. Colloid Interface Sci. 195 (1997) 121.

[24] J. Schultz, L. Lavielle, C. Martin, J. Adhesion 23 (1987) 45.

[25] C.J. Van Oss, R.J. Good, M.K. Chaudhury, Langmuir 4 (1988) 884.

[26] B. Maroufi, B. Ranjbar, K. Khajeh, H. Naderi-Manesh, H. Yaghoubi, Biochim. Biophys. Acta 1784 (2008) 1043.

[27] J.M. Sánchez, V. Nolan, M.A. Perillo, Colloids Surf. B Biointerfaces 108 (2013) 1.

[28] T.J. Yu, J.L. Lippert, W.L. Peticolas, Biopolymers 12 (1973) 2161.

[29] E.N. Lewis, W. Qi, L.H. Kidder, S. Amin, S.M. Kenyon, S. Blake, Molecules 19 (2014) 20888.

[30] S.R. Tello-Solís, J. Jiménez-Guzmán, C. Sarabia-Leos, L. Gómez-Ruíz, A.E. Cruz-Guerrero, G.M. Rodríguez-Serrano, M. García-Garibay, J. Agric. Food Chem. 53 (2005) 10200.

[31] P.J. Artymiuk, C.C.F. Blake, D.W. Rice, K.S. Wilson, Acta Crystallogr. B: Struct. Crystallogr. Cryst. Chem. B38 (1982) 778.

[32] C. Zhou, W. Qi, E.N. Lewis, J.F. Carpenter, Anal. Biochem. 472 (2015) 7.

[33] S. Jang, J. Jang, W. Choe, S. Lee, ACS Appl. Mater. Interfaces 7 (2015) 1250.

[34] A. Torreggiani, M. Di Foggia, I. Manco, A. De Maio, S.A. Markarian, S. Bonora, J. Mol. Struct. 891 (2008) 115. 
458 [35] A. Torreggiani, M. Tamba, I. Manco, M.R. Faraone-Mennella, C. Ferreri, C. Chatgilialoglu, $459 \quad$ J. Mol. Struct. 744 (2005) 767.

460 [36] C. Sun, J.C. Berg, Adv. Colloid Interface Sci. 105 (2003) 151.

461 [37] Y. Tanaka, A. Kagamiishi, A. Kiuchi, T. Horiuchi, J. Biochem. 77 (1975) 241.

462 [38] M.C. Vaney, S. Maignan, M. Riès-Kautt, A. Ducriux, Acta Crystallogr. D. Biol. Crystallogr. $46352(1996) 505$.

464 [39] C. Chaiyasut, Y. Takatsu, S. Kitagawa, T. Tsuda, Electrophoresis 22 (2001) 1267.

465 [40] J. Baardsnes, P.L. Davies, Biochim Biophys Acta. 160 (2002) 49.

466 [41] S. Pezennec, F. Gauthier, C. Alonso, F. Graner, T. Croguennec, G. Brulé, A. Renault, Food 467 Hydrocolloids 14 (2000) 463.

468 [42] M. Jurkiewicz-Herbich, A. Muszalska, R. Słojkowska, Colloids Surfaces A: Physicochem. 469 Eng. Aspects 131 (1998) 315.

470 [43] G.I. Makhatadze, P.L. Privalov, Biophys. Chem. 50 (1994) 285.

471 [44] U.V. Shah, Z. Wang, D. Olusanmi, A.S. Narang, M.A. Hussain, M.J. Tobyn, J.Y. Heng, Int. 472 J. Pharm. 495 (2015) 234.

473 [45] X. Han, L. Jallo, D. To, C. Ghoroi, R. Davé, J. Pharm. Sci. 102 (2013) 2282. 